\title{
Degree Models in Biomedical Engineering
}

\author{
G. E. Avendaño ${ }^{\psi}$, A. J. Rienzo
}

Biomedical Engineering School, Universidad de Valparaíso, Valparaíso, Chile

Abstract - In this paper, the authors have carried out a systematic study and review of a set of researches and publications, regarding the theme of how to improve training programs in biomedical engineering, and make a contribution to the specialization in the area of clinic engineering.

Keywords - Biomedical Engineering Programs, Models, Curricular Design, Biomedical Engineering Education.

\section{MODELOS DE TITULACIÓN EN INGENIERÍA BIOMÉDICA}

Resumen - En este artículo, los autores han realizado un estudio y revisión sistemática de un conjunto de investigaciones y publicaciones sobre el tema de cómo mejorar los programas de capacitación en ingeniería biomédica y contribuir a la especialización en el área de ingeniería clínica.

Palabras clave - Programas de Ingeniería Biomédica, Modelos, Diseño Curricular, Educación en Ingeniería Biomédica.

\section{Modelos de Grado em Ingeniería BiomédicA}

Resumo-En este trabajo se ha realizado um estudo e revisão sistemática de um conjunto de pesquisas e publicações sobre o tema de melhorar os programas de capacitação em engenharia biomédica e contribuir para a especialização na área de clínica ingenieria.

Palavras-chave — Programas de Engenharia Biomédica, Modelos, Projeto Curricular, Educação em Engenharia Biomédica.

\% Author's Mailing Address: guillermo.avendano@uv.cl

DOI: https://doi.org/10.24050/19099762.n22.2017.1186 


\section{INTRODUCTION}

A ccording to a systematic investigation, one can argue that the career or specialization in biomedical engineering (BME) is a relatively new multidisci-plinary profession (no more than 7 decades in the world, and no more than 5 decades in Latin America) [1], and therefore, several investigations and publications have been made on what is or what a biomedical engineer does, and the different problems or factors that can influence their formation [2]. Biomedical engineering is a growing discipline in Latin America. The region has one million beds distributed among its 14,000 hospitals. Residents in rural areas have poor access to primary care, as most hospitals are located in major cities or capitals. These main hospitals require a growing number of clinical engineers. This subdiscipline (Clinical Engineering) represents almost 40\% of staff, projects and grants in the BME field [3].

Among the topics associated with the training of biomedical engineers, which have been analyzed, socialized and are frequently discussed among peers, we find:

- The concept of relevance, that is, whether the training should be of a general or specialized nature; Defining the real scope of their work performance.

- The contents of the subjects and programs of study that must be given to the students; Differentiating and quantifying hours in courses in basic sciences, engineering sciences, and applied sciences or specialization; - If the modality of study, must be undergraduate or only postgraduate.

- The teaching materials and the necessary minimum infrastructure (laboratories), for an adequate formation; and the theory-practice relationship to be achieved.

- The concept of professional relationship with the real world, i.e. how the training and experience of teachers, as well as the curricular subjects, lead to train professionals competent for their insertion in the world of health.

\section{Methods AND Models}

On the basis of a set of publications, both bibliographic resources of the IEEE (such as "Biomedical Engineering Education and Society" and the Xplore base), publications in Biomedical Engineering Congresses (such as CLAIBs and IFMBEs), The authors present a series of data and approaches about which are the subjects that are currently debated on the education programs in Biomedical Engineering including clinical engineering. Historical background was gathered, how programs of study and careers were initiated in what we currently recognize as biomedical engineering; both in Europe, USA and in Latin America [1, 4-6]. We also analyzed the technological and social factors that enhance the need for biomedical equipment, and of professionals who take care of them. The main ones are:

a) There are several statistics about the growing number of manufacturers and models of medical equipment and devices. The design and construction of equipment is currently unviable only with the participation of other engineers (electronic, electrical, industrial, mechanical), as was done decades ago; since biological knowledge as biophysical, physiological and anatomical concepts are essential in the formation of BME.

b) Likewise, the safety aspects of the patient and of the personnel who attend to him, are of high relevance. And the technical aspects related to the certification of the devices, can only be valued and understood by the specialists.

c) The demographic transition and the greater life expectancy (aging) of the population, generate a constant increase of the attentions and health benefits (and their associated cost).

d) The morbidity transition (where the incidence of infectious diseases is dramatically reduced and oncological, cardiologic, degenerative and accidents increased); And the prevalence of chronic diseases (such as hypertension, cholelithiasis, obesity, diabetes and respiratory diseases), where equipment such as multiparametric monitors, pressure meters, servoventilators, clinical laboratory equipment, image systems and others are widely used.

e) The new models of health care, and the transition of the health care network, where greater attention is increasingly required for first care (with an increase in equipment for imaging, spirometry, basic clinical laboratory, electrocardiography and Minor surgery). In addition, several studies have been carried out [7, 8], in which to compare undergraduate programs within the Latin American countries, information was obtained from the catalogs of courses offered by universities with BME undergraduate programs, through its website, trying to find the most up-to-date data.

A recent study by specialists from the Metropolitan Autonomous University (Mexico) [9] showed that in Latin American countries the number of institutions offering biomedical engineering programs was shown in Table 1; Where the cases of Mexico (48), Colombia (13) and Brazil (12) stand out. It is necessary to analyze whether there is a demand in Mexico and Colombia that justifies the existence of so many programs offered [10]. 
In several countries, programs in BME (Biome-dical Engineering) are supposedly based on the professional field requirements in which the graduate will develop, so some models have a high content of basic sciences, because the main demand comes from biomedical research institutions. On the other hand there are careers very involved in the design of medical devices, since their ties with the medical equipment industry is a priority; While in most Latin American countries, the most demanding professional field is related to biomedical technologies in the hospital world, a specialty known as clinical engineering [11]. Both in management of devices as in evaluation and certification, these tasks are increasingly important, because the impact of errors and failures of devices (technical iatrogeny) is critical today. Throughout the history of the training of professionals in the specialty, we have several models that have been implemented not only in the temporal sense, but in the performance context of the professionals created.

Table 1. Countries and Numbers of Institutions offering BME Programs [9]

\begin{tabular}{cc}
\hline Country & Number of Programs \\
\hline México & 48 \\
Colombia & 13 \\
Brazil & 12 \\
Argentina & 7 \\
Chile & 2 \\
Honduras & 1 \\
El Salvador & 1 \\
Perú & 1 \\
Bolivia & 1 \\
Cuba & 1 \\
Venezuela & 1 \\
Paraguay & 1 \\
Ecuador & 1 \\
\hline
\end{tabular}

Based on the study of the different programs, we can establish that the following training models exist:

A. Scientific Model based on Biological Sciences: This first model is introspective, with teachers focused on high scientific research, with a deep mathematical and physical component, making extensive use of computers. His professional purposes are generally diffused, rather academic; the results of the research activity that is generally plenty, are projects with results destined to publish in magazines preferably of high level and to elaborate papers in congresses. The professors are mostly professionals with low insertion in the world of Health and restricted to their activity in the academic world. The resulting product of this type of school are graduates who learn in their places of work through the empirical way subjects that they did not study in the academy, often expressing their complaints of this situation; Are professionals with little demand from the business world for the solution of specific health problems.

B. Management Model based on clinical engineering: This model focuses on the wide variety of generic problems in the hospital world; Inclination to the solution of the problems of management, administration and its relation with the equipment. It is strongly embedded in the world of clinical engineering; many teachers have a real link with the hospital world, have been engineers in Health Institutions or consulting companies. Its advantage is in the successful contribution in the management of actual technologies. The weakness of this model is the shallow depth in the subjects of hard engineering, design, construction and testing of devices; also have low insertion in the world of the biomedical investigations of high exigency.

\section{Model Based in Technology for Technical} Service: In this model maintenance is the core of training. It is a very emergent model in recent years, derived from electronic engineering, industrial and / or mechanical engineering; With the pretension of covering professionally the wide field of demand in biomedical engineering; Many of the creators of these careers start from the old paradigm of conversion or later specialization to a discipline of near or pertinent undergraduate, returning to the concept prior to the creation of Biomedical Engineering, consisting in training professionals from complementing the training in electronic engineering with Biological or biomedical knowledge and concepts related to devices. The curricula is usually a summation of diverse subjects, some disjointed; and the who have management capacity, can aspire and sometimes reach management positions; Their weakness is in the low competition for the development of technologies and they are not valued like professionals in the field of the hard technologies required by companies of the biomedical field. The product resulting from this type of careers are graduates teachers staff is formed by a diverse range of professionals who "do what they can or what they know", and the graduating professionals find little relation of the theoretical contents studied with the daily requirements in their professional activity. The existence of some teachers with real expertise (retired from companies or the hospital world) is an eventuality and not an expressly sought purpose. As a result product in this case, the curricula have a few years of study and a varied repertoire of subjects with a focus to meet the demands of medical equipment companies; Graduates 
find serious limitations to impact the decisions of the hospital world and they are relegate themselves to purely technical tasks.

D. Hospital Engineering Model: The hospital model, is inclined to meet the demands of hospital design, and focuses on hospital engineering with the link with architecture and hospital engineering. These courses are usually specializations or postgraduate courses from other disciplines such as Industrial Engineering, Electronics and Architecture, making the student to get a mention or specialization in very limited subjects. As a result, graduates of this type of professional have the syndrome of "permanent deficiency", feel orphan of certain knowledge, such as medical biological aspects, and are closer in the professional practice to architects or administrators than to Health professionals.

E. Mixed Technical Scientific Model: It is theoretically the most suitable, it allows the formation of competent professionals to solve problems of the electro-medical industry, technical service and clinical engineering (both in hospitals and clinics). It enables graduates to develop research at different levels of knowledge. These are usually programs of very varied subjects and with different levels of depth. Graduates can successfully perform in research centers, in the hospital world or in equipment companies both in manufacturing and in technical support. Its thematic contents are very broad and for this model to work requires teachers with good theoretical training in a very varied range of real specialties, along with a previous or simultaneous performance in the extra-university world (hospital or business sector). As a result, professionals of this type of careers have changed the world; are responsible for technological developments that have impacted the world of health. Their insertion is successful in research and development centers, and they are very well received by other professionals in the field of health who consider them peers. They also perform well in the world of clinical engineering and hospital management.

\section{Results AND Proposals}

From the analysis of the specialized literature [3, 8, 1113], the following proposals can be made:

A. Pertinence and Professional Training: Biomedical engineers have the known dilemma of their available cognitive ability in relation to their professional performance, since they can be a very specialized professional when deepening in few subjects (ignoring others), or have a general knowledge adaptable to the requirements of the practice, without being a specialist in any specific subject. The external reality and the world of work is the one that demands the knowledge of the professional, and that in theory sets the terms and requirements in the type of training; But this is an aspect that is not always considered in the Universities at the time of the elaboration of contents and curricula. The proposal is that the ideal situation should be given with extensive training in subjects and deep in content, so that the professional must be a vast connoisseur of a variety of technologies related to health, and from various perspectives. Therefore, it is necessary to define the true scope of professional performance of the graduate, and if the training delivered corresponds to that performance.

B. Subject and curriculum contents: The study of the different training strategies in biomedical engineering in Latin America (and in the world), requires considering what are the so-called "core subjects" (or core of the specialty) that must be present in the curricula.

There are numerous studies in this respect, but we can agree that these should be:

- Medical electronics (biological measurement, bioinstrumentation, biomagnetism)

- Biomedical signals and images

- Mechanics (biomechanics, biomaterials, thermodynamics, optics)

- Mathematics (modeling, simulation)

- Computing and communications (telemedicine and interoperability)

- Projects (design and construction of equipment and systems)

- Clinical engineering, hospital safety, device certification

- Medicine and biology (anatomy, biophysics, physiology, pharmacology).

However, we are looking for a basic set of knowledge and skills that we call "key content." The key content could be covered in different ways in different universities. In addition, engineering schools around the world are reexamining their programs in accordance with international accreditation criteria. This process aims to incorporate the study of professional responsibility and ethics, along with an understanding of the social and environmental impacts of engineering decisions.

C. Modality of studies Undergraduate Postgraduate: With the rapid development of new technologies it is very difficult to include the latest technology in undergraduate courses. A solid theoretical 
basis should therefore be provided as a way of ensuring that undergraduate students are capable to absorb the latest technical developments on their own; But postgraduate studies should be complementary to undergraduate courses. The old dilemma of generalization versus specialization is particularly applicable to the situation of a broad discipline such as biomedical engineering. In addition, in view of the limited duration of any university career, postgraduate courses should be designed to exceed the very broad reach of undergraduate courses, providing graduate students with in-depth knowledge in specific fields. All universities must formalize lifelong learning for their graduates. The primary goal of continuing education in engineering is to help practicing engineers keep up with the technological advances relevant to their current or future jobs.

D. Teaching materials and the necessary minimum infrastructure (laboratories): Any modern educational program should make good use of the technological tools and teaching tools currently available: the web, the media (DVD, software, etc.). These are particularly useful for continuing education. Human and material resources are needed for training, namely: on the one hand qualified teachers (overcoming the initial improvisation) through an international policy of improvement (should a Latin American plan be established?). The material means to generate texts, presentations, equipment or laboratories and specialized didactic material for the teaching of high performance. It is also necessary to achieve uniformity in national and Latin American training; Have a common language to understand similar contents.

E. Training of teachers, and the relationship with the real world: The real world's requirements for the University to train the best engineers are complex and it is not always possible to put them into practice, and what is worse, not always exist channels to detect what the real needs are and what is the best program to meet the adequate professional profile. This indicates that it is necessary to get professionals equipped with the necessary tools, to make a much needed sustained action of the management of the technology, tending to the optimization and saving in these resources; these insurance measures will have a beneficial impact on public health in general. Consideration must be given to the preferential recruitment of more experienced professors in the professional activity (equipment industries, equipment marketing companies and health institutions) than those who only have academic experience in universities. The effective application of the links between universities and health institutions or companies through visits or internships of students to institutions and vice versa, professionals in various areas should go to the classroom for discussions, symposia, conferences and seminars on topics around Real world of biomedical engineering. The analysis and proposals mentioned above are closely interrelated. For example, in the case of relevance and professional training, Fig. 1 shows the relationship between specialized knowledge and general training, and its effect on professional competence. The training directed from the firsts years in the specialty of the BME, allows the student to have, on the one hand, a clear vision of their future work, since daily they are watching during their studies, the thematic, the equipment, and the problems that will be his professional work in the short term, and on the other hand, helps him to increase the relevance of his studies in relation to the future work activity.

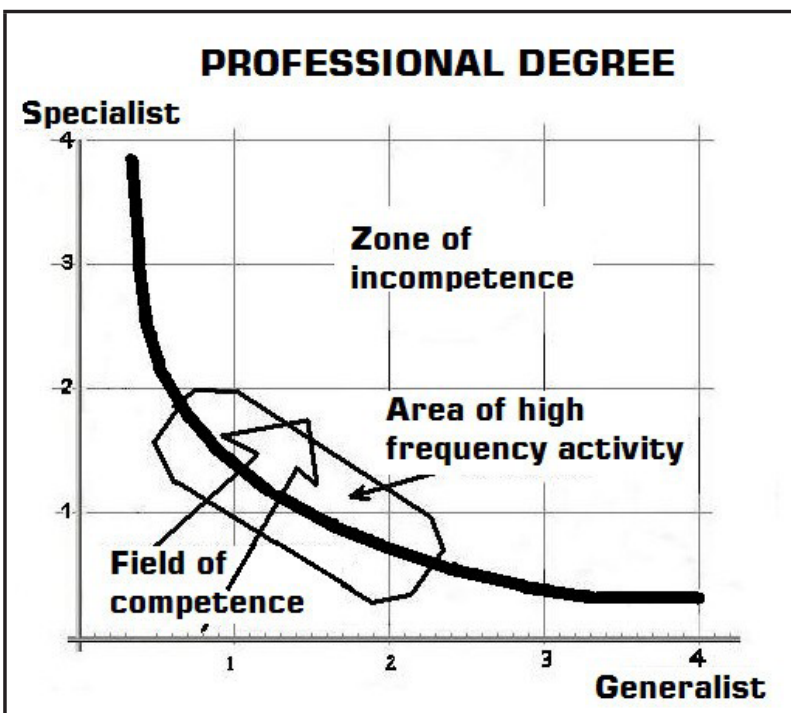

Fig. 1. Professional Degree in BME. [1]

\section{CONCLuSION}

The profession of Biomedical Engineering is conceptually dynamic and its scope is often extended to incorporate new disciplines and specialties. Therefore, BME education must be adaptable and multidisciplinary, since it is education for other fields of powerful engineering and rapid movement [3]. Biomedical engineering education faces some classic and new challenges. The proposal is to train qualified professionals who know the real problems and the necessary tools to adequately solve the problems of all existing technological systems in the world of human and animal health. It is necessary to obtain a correct curricular structure based on reality and not only in terms of theoretical abstractions, this is of great importance to have a positive impact on health through the job performance of graduates. 


\section{REFERENCES}

[1]. G. Avendaño (2007): 'La Formación en Ingeniería Biomédica: Aspectos característicos de una innovación curricular en la Universidad de Valparaíso"; II Seminario Internacional Innovación Curricular en Educación Superior, Universidad de Valparaíso; Impresos El Mercurio de Valparaíso, Valparaíso, 2007; Págs.: 53-68.

[2]. R. Linsenmeier (2003): "What Makes a Biomedical Engineer?"; IEEE Engineering in Medicine and Biology Magazine; July/ August, 2003; Págs. 32-38.

[3]. J. Monzon (2005): "The Challenges of Biomedical Engineering Education in Latin America"; Proceedings of the 2005 IEEE Engineering in Medicine and Biology 27th Annual Conference; Shanghai, Chine; September 1-4; Págs. 2403-2405.

[4]. T. Harris, J. Bransford and S. Brophy (2002): "Roles for Learning Sciences and Learning Technologies in Biomedical Engineering Education"; Annual Rev. Biomedical Engineering 2002; Extraído de: www.annualreviews.org

[5]. D. Gatchell, R. Linsenmeier and T. Harris (2004): "Biomedical Engineering Key Content Survey - The 1st Step in a Delphi Study to Determine the Core undergraduate BME Curriculum; Proceedings of the 2004 American Society for Engineering Education Annual Conference; American Society for Engineering Education.

[6]. J. Nagel (2007): "Medical and Biological Engineering and Science in the European Higher Education Area"; IEEE Engineering in Medicine and Biology Magazine; May/June, 2007; Págs.18-25.

[7]. J. Azpiroz-Leehan, F. Martínez, E. Urbina, M. Cadena and E. Sacristán (2016): "Defining New Aims for BME Programs in Latin American"; 38th Annual International Conference of the IEEE Engineering in Medicine and Biology Society (EMBC); Págs. 4333-4336. DOI: 10.1109/EMBC.2016.7591686.

[8]. R. Allende, D. Morales, G. Avendaño and S. Chabert (2007): "Biomedical Engineering Undergraduate Education in Latin American"; 16th Argentine Bioengineering Congress and the 5th Conference of Clinical Engineering; IOP Publishing Lyd. DOI: 10.1088/1742-6596/90/1/012019.

[9]. J. Azpiroz-Leehan, F. Martínez-Licona, E. Urbina-Medal, M. Cadena and E. Sacristán (2016): "Biomedical Engineering in Latin America: A Survey of 90 Undergraduate Programs"; 38th Annual International Conference of the IEEE Engineering in Medicine and Biology Society; Walt Disney World Resort, Orlando, USA; August 17-20, 2016.

[10]. A. Zárate (2014): "Se requieren cerca de 12 mil ingenieros biomédicos al año en México y sólo se están produciendo 800"; Sala de Prensa, Laurate International Universities; Universidad del Valle de México, 27 de Marzo de 2014. Extraído de http:// laureate-omunicacion.com/prensa/copbiome/

[11]. G. Avendaño and A. Rienzo (2016): "Programs in Biomedical Engineering Education: How to Improve it"; VII Congreso Latinoamericano de Ingeniería Biomédica CLAIB 2016; Bucaramanga, Colombia.

[12]. J. Monzon and A. Monzon-Wyngaard (2009): "Ethics and Biomedical Engineeering Education: the continual defiance"; 31st Annual International Conference of the IEEE Engineering in Medicine and Biology Society; Minneapolis,USA; September 2-6, 2009.
[13]. T. Harris, and S. Brophy (2005): "Challenge-based instruction in biomedical engineering: A scalable method to increase the efficiency and effectiveness of teaching and learning in biomedical engineering"; Medical Engineering \& Physics; Elsevier, 2005; Págs. 617-624. 